УДК 316.752(=512.31)

ЗАТЕЕВА Надежда Александровна - кандидат социологических наук, доцент ВосточноСибирского государственного института культуры (670031, Россия, Республика Бурятия, г. УланУдэ, ул. Терешковой, 1; z.n.a.-79@таil.ru)

TAТАРОВА Светлана Петровна - доктор социологических наук, доцент Восточно-Сибирского государственного института культуры (670031, Россия, Республика Бурятия, г. Улан-Удэ, ул. Терешковой, 1; Svetlana.tatar@inbox.ru)

ЭРХЕМТОГС Жугдэрнамжил - Ph.D, Монгольский государственный университет искусств и культуры (21064, Монголия, г. Улан-Батор, округ Сухэ-Батора, 11, корп. 2; erkhemtugs@gmail.com)

\title{
ЭТНИЧЕСКИЕ ЦЕННОСТИ КАК ОСНОВА ГРАЖДАНСТВЕННОСТИ
}

Аннотация. В статье рассматривается значение этнических ценностей в формировании гражданственности. На материалах эмпирических исследований, осуществленных авторами, сравниваются ценности, распространенные у монголов и бурят. Представители этих двух этносов сохранили общность в аксиосфере. Семья, традиционные ценности, национальная идентичность занимают важное место в системе ценностей современных бурят и монголов. Наличие таких ценностей свидетельствует о высоком уровне гражданственности бурят и монголов.

Ключевые слова: гражданственность, ценности, этнические ценности, этнос, монголы, буряты

$\mathrm{H}$ аучное обсуждение понятия и структуры гражданственности имеет продолжительную историю. Начавшись в античный период, оно не прекращается до сих пор. Российские исследователи на протяжении всей эволюции отечественной научной мысли активно интересовались проблемой гражданственности в рамках философии, социологии, политологии, психологии, педагогики, культурологии и других наук. С одной стороны, это обогатило научный дискурс по данной проблеме, с другой - обусловило противоречивость как в понимании феномена, так и в использовании термина «гражданственность». Сравним политологический, педагогический и культурологический подходы к исследованию гражданственности. Толкование гражданственности в политическом контексте является наиболее распространенным, что связано с развитием концепции гражданского общества. С позиции политического подхода категория гражданственности рассматривается исследователями как «совокупность убеждений и взглядов, предполагающая, с одной стороны, высокую степень независимости и самостоятельности индивидуальных суждений об обществе, с другой нерушимую социальную солидарность, выражающуюся в участии человека в жизни социума» [Никифоров, Скалина 2007: 189]. Гражданственность членов общества выражается в их поведении, соблюдении возлагаемых на них обязательств, в инициативности, участии в различных сторонах жизни общества. Гражданственность предполагает наличие прав и исполнение обязанностей не только в личных, но и социальных интересах. Такие гражданские ценности и нравственные принципы, как социальная справедливость, равенство, свобода, толерантность, плюрализм и др., составляют основу гражданственности. Культура гражданственности служит мерой самореализации человека как гражданина не только в формально-юридическом, но и в нравственно-этическом и социокультурном смыслах [Рожкова, Васильева 2014: 123]. П.Л. Лавров и Н.К Михайловский вершиной проявления гражданственности считали внутреннюю готовность человека служить высшим 
целям, быть источником и движущей силой нравственного совершенствования общества [Никифоров, Скалина 2007: 189].

Психолого-педагогические исследования ориентированы на изучение гражданственности как интегративного качества личности, выражающегося в тех чувствах и состояниях, которые свидетельствуют об осознании человеком социальной роли гражданина, присущих этому статусу прав и обязанностей, о принятии гражданских ценностей, общественных норм и проявляются в активной социально значимой деятельности. Внимание педагогов-исследователей сосредоточено на том, что гражданственность, выступающая нравственным основанием поведения, «определяет сознательное и активное выполнение гражданских обязанностей и долга перед государством, обществом, народом; разумное использование своих гражданских прав, точное соблюдение и уважение законов страны»1.

Представление о гражданственности как феномене культуры характерно для культурологических исследований. Так, 3.Я. Капустина рассматривает гражданственность через призму общезначимых ценностей (гражданских благ), ценностных отношений (благочестие, добролюбие, умеренность, общественное благо как счастье каждого гражданина, взаимопомощь, забота, солидарность, понимание, согласие, дружба, свобода, толерантность, участие в государственном управлении, правосознание и др.), которые являются человеческим капиталом гражданского общества [Капустина 2008: 15].

Таким образом, общим для всех трактовок гражданственности выступает обращение к ценностям, этическим принципам как основным компонентам структуры гражданственности. В свою очередь, ценности имеют социальную природу и историческую обусловленность. Отечественные исследователи аксиосферы подчеркивают, что «ценности выступают не вспомогательной пристройкой к экономике и политике, а являются обобщенными представлениями людей о целях и нормах своего поведения», воплощают исторический опыт и выражают смысл культуры отдельного этноса и всего человечества. «Это существующие в сознании каждого человека ориентиры, с которыми индивиды и социальные группы соотносят свои действия» [Лапин 1996: 3]. В результате складываются конкретные типы поведения и отношения к протекающим в обществе социальным, экономическим, политическим процессам.

В рамках данной статьи авторы поставили задачу сравнить распространение традиционных ценностей у современных бурят и монголов. Данное сравнение интересно тем, что исторически данные этнические группы развивались в едином социокультурном пространстве, имели общие ценности. В настоящее время народы проживают в разных государствах, но имеют тесные культурные и экономические связи. Эмпирическую основу сравнительного анализа составляют результаты социологического исследования «Современное положение и тенденции национальных традиций и обычаев в семейном окружении», проведенного в Монголии и Республике Бурятия в 2018 г. Руководителем группы исследователей со стороны Монголии являлся заведующий кафедрой менеджмента Монгольского государственного университета искусств и культуры доктор Жугдэрнамжил Эрхемтогс, со стороны Республики Бурятия - декан факультета социально-культурной деятельности, наследия и туризма ВосточноСибирского государственного института культуры доктор социологических наук Светлана Петровна Татарова. Педагоги Монгольского государственного университета разработали инструментарий исследования, собрали эмпириче-

\footnotetext{
${ }^{1}$ Коджаспирова Г.М. Педагогический словарь. М.: Академия. 2001. С. 54.
} 
ские данные в Монголии. Коллектив Восточно-Сибирского государственного института культуры провел сбор данных в Республике Бурятия.

Рассмотрим ряд распространенных среди опрошенных респондентов ценностей, имеющих значение для понимания современной аксиоструктуры бурят и монголов. Интенсивность интеграции членов общества, разделяющих единые ценности, соотносится с уровнем распространения определенной ценности среди членов социума в конкретный исторический отрезок времени. Если эту ценность одобряет большинство членов общества, ее можно считать интегрирующей; если же ее одобряет меньшинство, то она оказывается дифференцирующей [Лапин 1996: 6]. Рассмотрим ответы респондентов на вопрос о семье, традиционно являющейся одной из базовых социальных ценностей. Отвечая на вопрос, что является самым важным и драгоценным в семье, и буряты, и монголы на 1-е место поставили «детей, супругов и родителей», 2-ю и 3-ю позиции заняли ответы «взаимное доверие» и «любовь». При этом монгольские респонденты превзошли бурят в предпочтении детско-супружеских и родительских отношений, в то время как вторые придают большее значение доверию и любви. Примечательно, что финансовое положение семьи достаточно значимо для $15,1 \%$ бурят, в отличие от монголов, среди которых лишь $3,4 \%$ указали данный вариант ответа. Более подробно ответы на этот вопрос представлены на диаграмме, приведенной на рис. 1.

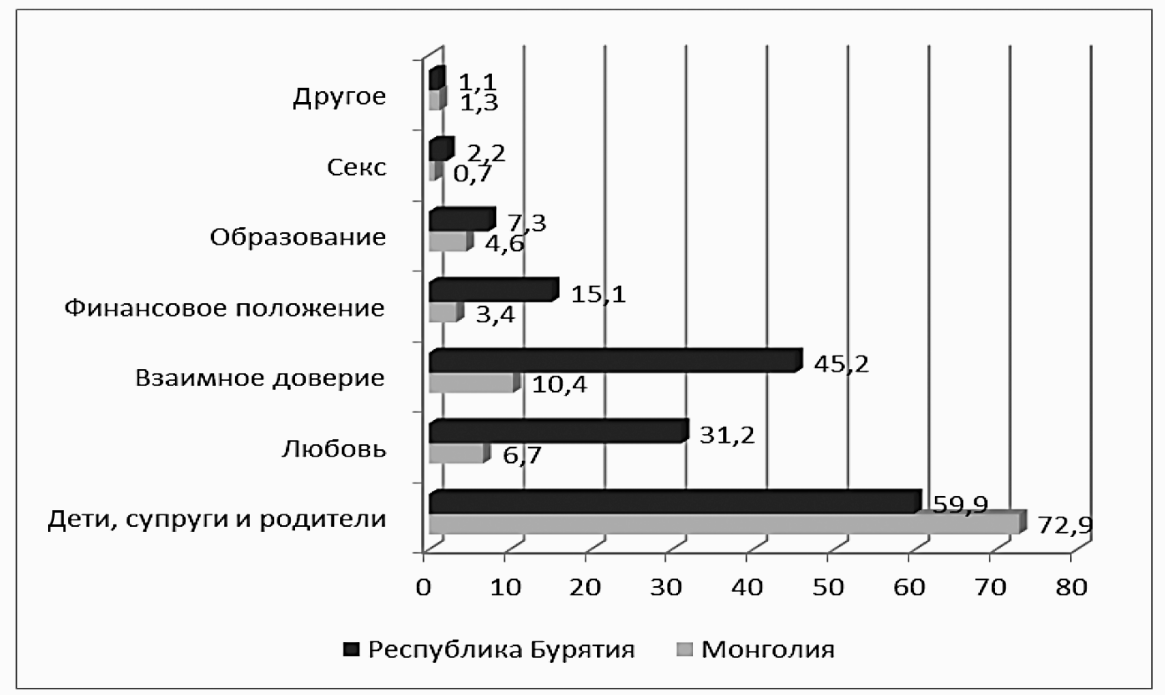

Рисунок 1. Распределение ответов респондентов на вопрос: «Что самое важное и драгоценное в Вашей семье?»

Структура семьи претерпела изменения, что подтверждается ответами опрошенных, отраженными на диаграмме, приведенной на рис. 2. Многопоколенная семья отошла на 2-е место у обеих групп респондентов, уступив 1-ю позицию нуклеарному типу семейной организации. Семья из одного родителя с ребенком оказалась на 3-м месте. Приведенные данные подтверждают разрушение традиционной структуры семьи. 
Мать - одиночка, одинокий отец с ребенком

Холостой /холостая/

Муж, жена, дети, родители, братья и сёстры

Муж, жена и ребенок /дети/

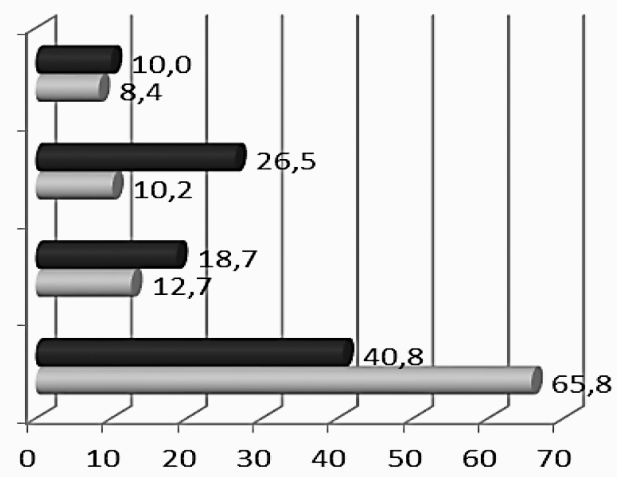

Республика Бурятия

Рисунок 2. Распределение ответов респондентов на вопрос: «Укажите состав своей семьи»

Кочевой способ ведения сельского хозяйства, исторически присущий монголам и бурятам, наложил отпечаток на национальную идентичность: индивиды однозначно идентифицировали себя с семьей, кланом, родовой общиной и т.д., поскольку они рождались как члены семьи, рода, этнической группы, а потому преобладающей являлась групповая идентичность. С развитием промышленности произошло ослабление семейных отношений и связей, вследствие чего наблюдается снижение значимости семейной идентификации и возрастает важность национальной. Особенностью проживания кочевых народов являлось то, что они имели очень тесные родственные связи и отличались четким знанием своей родословной (не менее чем до седьмого колена). В исследование был включен вопрос, насколько сегодня распространено знание своей родословной бурятами и монголами (см. рис. 3). По данному вопросу ответы бурят и монголов отличаются. Знание родословной подтвердили $66,1 \%$ бурят против $18,4 \%$ монголов, желание вести родословную в дальнейшем высказали 73,1\% монголов и $21,8 \%$ бурят. В целом, знание своих корней у преобладающей части

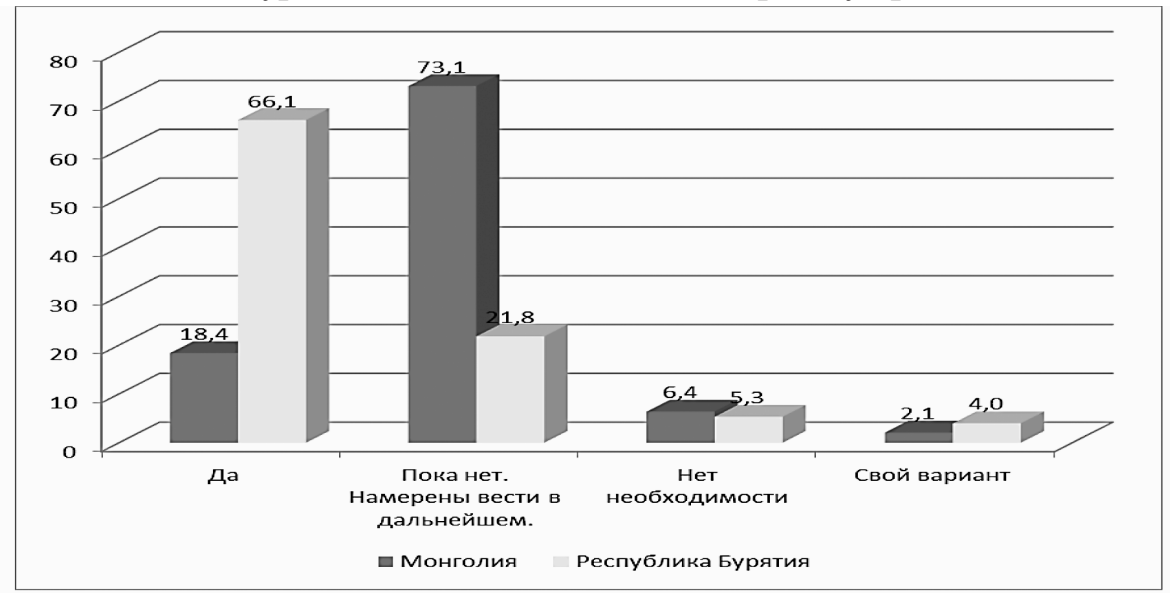

Рисунок 3. Распределение ответов респондентов на вопрос: «Знаете ли Вы генеалогическое древо своей семьи?» 
обеих групп опрошенных является важной ценностью, которую они унаследовали у предков и стремятся передать своим детям.

Высказанное респондентами мнение о семье, отраженное в приведенных выше вопросах, свидетельствует, что ценность семьи по-прежнему значима для представителей бурятского и монгольского этносов, несмотря на изменение типа семейных отношений и структуры семейной организации. Ценность семьи в контексте гражданственности представляет большое значение, так как это, во-первых, одна из социально одобряемых и значимых ценностей и в России, и в Монголии, во-вторых, семья - это социальная организация, на которую государство возлагает множество функций, институт, при помощи которого решаются вопросы национальной безопасности, демографической и экономической политики. Значимость ценности семьи среди населения, таким образом, позволяет государству рассчитывать на поддержку в реализации ряда политических задач. Согласно проведенному исследованию, и монголы, и буряты являются для своих государств достаточно надежной опорой в проведении семейно ориентированных мероприятий, реформ, политики в целом.

Показательным для этнического самосознания и разделения ценностей своего народа является отношение к традиционным праздникам. У бурят и монголов главным праздником является празднование Нового года по лунному календарю - Сагаалгана (бур.), или Цагаан сара (монг.). В отношении этого праздника респонденты были единодушны: для подавляющего большинства бурят и монголов (86,6\% и 90,9\% соответственно) это важно. Значимость этнического праздника свидетельствует о сохранении этнического самосознания и национальной идентичности, что соотносится с осознанием себя гражданами национальной республики в составе федерации (характерно для бурят) и национального государства (монголы). Это качество коррелирует с гражданственностью и соответствующим типом поведения.

Дополнительно у респондентов спрашивали, насколько для них приемлемо ношение национальной одежды, что также связано с национальной иденти-

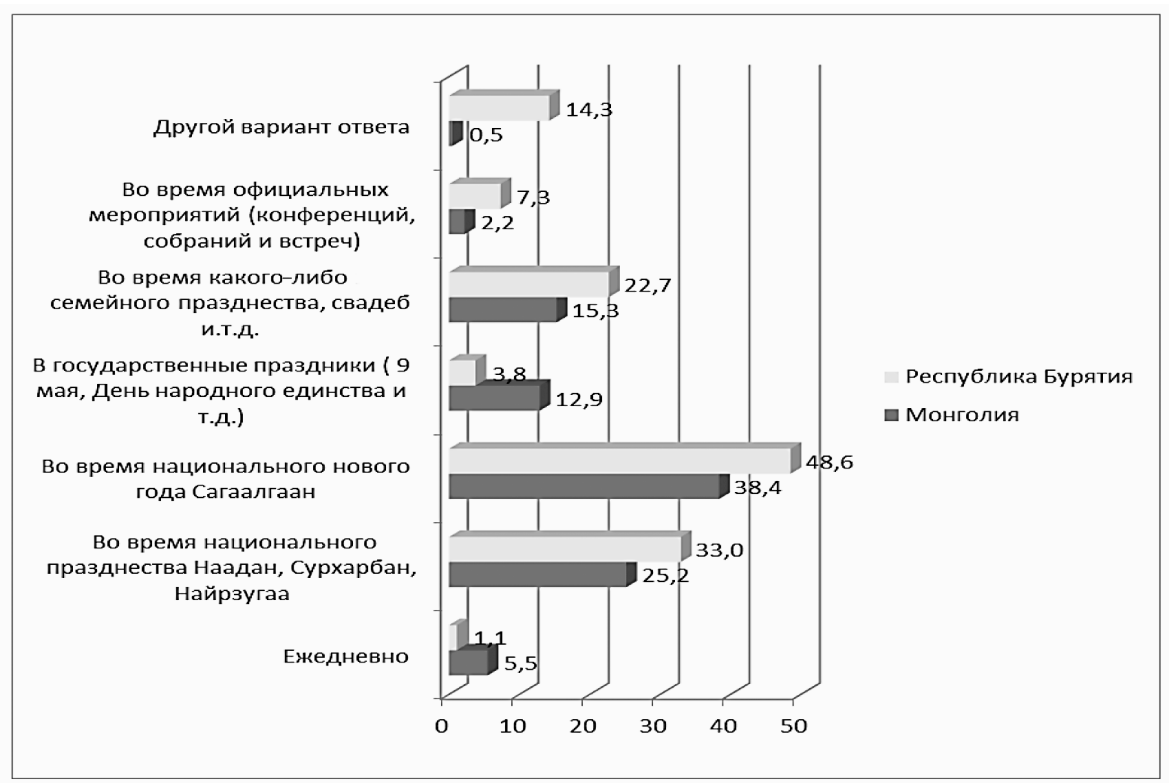

Рисунок 4. Распределение ответов респондентов на вопрос: «В каких случаях Вы носите национальную одежду? 
фикацией граждан. Согласно ответам, буряты и монголы чаще всего надевают национальную одежду на те мероприятия, которые связаны с этнической культурой (Сагаалган/Цагаан сар, Сурхарбан/Наадам) и во время семейных праздников (см. рис. 4). Полученные ответы подтверждают, что демонстрация национальной принадлежности присуща респондентам в специфических ситуациях - во время событий, где подчеркивается принадлежность к своему этносу.

Подводя итог сказанного выше, можно сделать вывод, что система ценностей бурят и монголов опирается на единые ценности. Историческое разделение и проживание в разных государствах обусловило определенное расхождение во взглядах, но оно не носит критический характер. Общность культуры и развитие в трансграничном социально-культурном пространстве поддерживает близость этих двух народов. Рассмотренные в статье ценностные аспекты демонстрируют высокий уровень гражданствености у бурят и монголов, для которых большое значение имеют семья, принадлежность к своей этнической группе, национальные традиции.

\title{
Список литературы
}

Капустина 3.Я. 2008. Гражданственность как ценность российской культуры: дис. ... д.культ. М. 334 с.

Лапин Н.И. 1996. О модернизации базовых ценностей россиян. - Социс. Социологические исследования. № 5. С. 3-23.

Никифоров Ю.Н., Скалина А.Н. 2007. О понятии «гражданственность». Вестник Башкирского университета. Т. 12. № 4. С. 188-191.

Рожкова Л.В., Васильева Н.Д. 2014. Гражданственность и патриотизм как основания социальной консолидации российского общества. - Мониторинг общественного мнения: экономические и социальные перемены. № 3(121). С. 123128.

ZATEeVA Nadezhda Aleksandrovna, Cand.Sci. (Soc.), Associate Professor at the East-Siberian State Institute of Culture (1 Tereshkovoi St, Ulan-Ude, Republic of Buryatia, Russia, 670031; z.n.a.-79@mail.ru)

TATAROVA Svetlana Petrovna, Dr.Sci. (Soc.), Associate Professor at the East-Siberian State Institute of Culture (1 Tereshkovoi St, Ulan-Ude, Republic of Buryatia, Russia, 670031;Svetlana.tatar@inbox.ru)

ERKHEMTUGS Jugdernamiil, Ph.D, Mongolian State University of Arts and Culture (bld. 2, $11^{\text {th }}$ khoroo, Sukhbaatar district, Ulaanbaatar, Mongolia, 21064; erkhemtugs@gmail.com)

\section{ETHNIC VALUES AS A BASIS OF CIVIC CONSCIOUSNESS}

\begin{abstract}
The article discusses the importance of ethnic values in the formation of citizenship. On the materials of empirical research carried out by the authors, the paper compares values, common among Mongols and Buryats. Representatives of these two ethnic groups retained commonality in the axiosphere. Family, traditional values, national identity occupy an important place in the value system of modern Buryats and Mongols. The presence of such values indicates a high level of citizenship of Buryats and Mongols.
\end{abstract}

Keywords: citizenship, values, ethnic values, ethnos, Mongols, Buryats 